Portland State University

PDXScholar

1978

\title{
The evaluation of a Title $X X$ training grant in child care treatment
}

Gilbért Louis Peña

Portland State University

Follow this and additional works at: https://pdxscholar.library.pdx.edu/open_access_etds

Part of the Social Work Commons

Let us know how access to this document benefits you.

\section{Recommended Citation}

Peña, Gilbért Louis, "The evaluation of a Title XX training grant in child care treatment" (1978).

Dissertations and Theses. Paper 2737.

https://doi.org/10.15760/etd.2731

This Thesis is brought to you for free and open access. It has been accepted for inclusion in Dissertations and Theses by an authorized administrator of PDXScholar. Please contact us if we can make this document more accessible: pdxscholar@pdx.edu. 
THE EVALUATION OF A TITLE XX

TRAINING GRANT IN CHILD CARE TREATMENT

by

GILBÉRT LOUIS PEN̄A

submitted in partial fulfillment of the requirements for the degree of

MASTER OF SOCIAL WORK

Portland State University

1978 
CHAPTER

I INTRODUCTION . . . . . . . . . . . . . . 1

II LITERATURE REVIEW . . . . . . . . . . 2

III PROCEDURES .............. . . 10

IV FINDINGS . . . . . . . . . . . . . 14

V Summary and Conclusions. . . . . . . . .27

BIBLIOGRAPHY . . . . . . . . . . . . . . . 29

APPENDIX .................... . . 33 


\section{INTRODUCTION}

The focus of this paper is two-fold. First to evaluate a course in child care treatment, and, second, while doing so, to trace the evolution of child care as a profession. The course being evaluated here was not an isolated event. It was a small part of a national movement to upgrade child care and the child care worker. This is a young, upcoming profession in its developmental stages. Consequently, many of the issues and training methods presented here will be improved and become more sophisticated by the time this paper is printed.

At the same time there is a need to keep interested persons informed and knowledgeable about the state of the art. It is for this reason that the evaluation of this particular course, a microcosm in the world of child care, has been presented in the context of the overall picture. It is also important to keep in mind that because of the dynamic nature of the child care field, this report is, in effect, a snapshot in time. It should be viewed in these terms. It is hoped that this contribution will serve as an appetizer to a very exciting field of professional accomplishment. 


\section{LITERATURE REVIEW}

\section{The Polemics of Professionalization}

Recent literature emphasizes the emergence of the child care worker as a new professional in the mental health community. The role of the child care worker is discussed as a difficult one (Birnbach 1973) requiring a great deal of skill and self-discipline. The child care worker has historically been considered a subordinate member of the child mental health team. However, because he functions as a parent model or substitute (Rieger, 1974, Katz, 1970, Alder, 1973), providing for the child's maternal as well as instructional and therapeutic needs (Larsen, 1973, Barnes and Kelman, 1974) he is in a vital position in the treatment process. He consequently needs improved skills as he evolves from a custodial to a treatment person (Gordetsky, 1974, Rozentals, et.al., 1974, Conningham, 1975, Toigo, 1975)

Goocher (1971) recognizes a dichotomy between the child care workers and therapists in treatment settings and emphasizes the need to expand the child care worker's role in the treatment process. Because he is part of the child's environment and shares the child's daily experiences, he is in the best and most informed position among the treatment team members and can exert the greatest therapeutic impact on the child.

This idea is supported by Portnoy, Billier and Davids (1972) who have stated that the child care worker has the 
most potential to produce therapeutic gains and may well be the most powerful figure in residential treatment. This is due to the fact that in "milieu therapy" the thrust of treatment is in the child's everyday experiences rather than individual therapy. Beker (1975) concurs, stating that it is the child care worker who orchestrates and coordinates all of the resources available to the child, enabling him to experience these as an integrated whole in the service of his development. Moreover, the report of the Standards Committee of the Washington Conference of Child Caring Institutions (Foster, 1973) defined the child care worker as the person responsible for the child's daily care and living experiences, and Maier (1971) proposes that the child care worker needs to be a partner in the implementation of the total organizational program.

While examining the notion of the child care worker as a professional Beker (1973) goes on to state the necessity for a wholistic approach to child care. This means that professional child care workers need expertise with normal children as well as disturbed children and competence in a variety of settings. He states:

This is somewhat analogous to the Social Work field, where group work is largely oriented toward enhancing the growth and functioning of "normal" clients and provides a different perspective from that of casework, which typically deals with people's problems.

The idea of a child care professional is also likened by Beker (1973, 1973a) and Barnes \& Kelman, (1974) to the 
European "Educateur"; the name given to a recognized child care profession which includes specialized training, a distinct career ladder and a respected position in their professional community.

The "state of the art" in the United States is, given this comparison, somewhat retarded. However, there is evidence to suggest that we are headed in a similar direction for example, Bayduss, et.a1. (1972), report on the success of an experiment where child care workers replaced psychologists in testing and other diagnostic procedures. In another case in point Ziegler (1972), Foster(1972), Klein \& Weathersby (1973), Toigo (1975) have reported on the Child Development associate, a new professional created by the U.S. Office of Child Development in 1972. The creation of this position was aimed at alleviating the shortage of qualified personnel in "Head Start" and day care settings. Not everyone is in agreement concerning the need for and method of professionalization. Whittaker (1974) maintains that child care expertise can be included in existing disciplines such as social work. English (1977) in his survey of recent literature reports on this and other controversies. He and Whittaker (1973) conclude that it is the responsibility of child care workers, their supervisors and board members, and state and federal legislators to decide on these issues.

Rieger and Devries (1974) maintain that the treatment. 
of children is sufficiently different from adults to create the need for a new professional equipped with unique skills. Reiger (1974) further suggests that current practice in the treatment of mentally ill children is a waste of time and money, citing the level and quality of training of the care givers as an important reason. The expanding body of child care knowledge (Reiger and Devries, 1977), the large numbers of children in need of care, and the lack of professional personnel qualified to treat and care for them gives rise to the justification for the creation of a new professional, named by Reiger (1974) the "Child Mental Health Specialist." The notion that child disturbances are becoming more complex and more difficult to deal with is supported by Redl (in Vanderven 1975) and Weintrob (1974) and the need for professionalization and/or improved training of the child care worker is also frequently supported (e.g. Maier, 1971, Hughes, 1973, Rieger \& Devries, 1977, et.al.)

Training the Child Care Worker

Foster (1973a) reporting on the dissatisfaction of the New York Association of Child Care Workers over child caring standards states:

It seems evident that the lack of specific, professional requirements for supervisory and line child care personnel reflects in part the relative lack of professional identity and training in the field.

Peters, et. al. (1974) maintains that certification of child care workers and training are inseparable concerns and that 
child care personnel:

.....constitute a coherent unit of the human services work force rather than a loose connection of separate units with disparate training and qualifications.

Hughes (1973) while discussing the issue of a need for a viable career ladder for child care workers states that "higher" positions require that the care givers have more education, training and experience and further maintains that "horizontal" movement is necessary and may be achieved by creating specializations as part of training.

In a survey of existing child care training courses, Beker (1973) queried providers of training about their needs. Communication and coordination among training programs and articulation of training with standards of practice were the two most frequent responses. In this context, literature about the evolution of the "Child Development Associate" by the federal government (Ziegler, 1972 and Foster, 1972) point out that it is in the realm of training that this new professional is most unique. Throughout the 1iterature, regardless of other issues, such as how professionalization may be achieved or how the child care worker relates to the treatment team, improved training of child care personnel is blatantly consistant.

The uniqueness of the child care worker's role, function and position in the treatment setting make him different from other student populations. Katz (1975) maintains that the educational needs of child development per- 
sonnel are related to their learning histories and life styles which are significantly different from traditional students served by universities and colleges. Peters, et. al. (1974) and Vandivier (1975) support this notion, asserting that training programs must be relevant to the trainees involved, be flexible enough to accommodate their individual differences, experiences, style, learning rate, objectives, and be committed to emphasizing practical information and flexibility.

It is also evident that a fresh approach to training is not only needed but is in the process of being developed. Cordori and Cowles (1971), while reporting on their experience with training child care workers at the University of Pittsburgh, School of Medicine, explained that typical academic measures and experience with children were unrelated to performance ratings by faculty or field supervisors. Ziegler (1972) and Foster,(1972) are adamnant about the notion that credentials for the new "Child Development Associate" be based on demonstrated competency rather than completion of courses or acquisition of credit hours. Swift (in Vanderven 1975) maintains that training must provide more than facts and theories. Child care personnel must learn to respond effectively and, consequentially, training must impart value in and facilitate a sense of individual worth, professionalism and personal growth. Rieger (1974) asserts that: 
One cannot treat mentally ill children by untrained or inadequately trained personnel, or by people who have been trained in the care and treatment of only adult mentally ill patients.

Rieger and Devries $(1974,1974 a)$ have cited the need and demonstrated the feasibility of training child care specialists, on various levels (A.A., B.A., M.A.) using a clinical and integrated academic approach. In his keynote address at the first graduation of masters level students in child care, at California's. Camarillo State Hospital, Rieger (1973) emphasized the fact that this was the first time graduates had been wholly trained and educated in a clinical setting, by clinically oriented, experienced and active members of an interdisciplinary team.

Training Child Care Workers in Oregon

Responding in part to the dearth of available training for child care personnel in Oregon, Ray and Lin Peterson, both child care practitioners and Michael Ebner, a clinical psychologist undertook the creation and delivery of a course of study targeted to the specific requirements and peculiarities of child care workers. They piloted the course in 1972 . It was originally conceptualized as a series of courses delivered by Ray Peterson and Michael Ebner. In 1973 Lin Peterson joined the instructional team and the concept of a team of three instructors delivering a single course, as opposed to separately delivering a series of courses was established. 
Also by 1973 the "Child Care Treatment and Assessment"course had evolved into a twelve credit training package, delivered by the instructional team as a group over three academic quarters and culminating in a one year certificate of accomplishment in child care from the School of Social Work, Division of Continuing Education at Portland State University. By 1974 the course had evolved into an eight hour per day workshop format meeting on alternate weekends. By 1976 the instructors had begun to experiment with the notion of meeting on two continuous days on alternate weekends. This format was well received and in 1976 the instructors were awarded a federal grant to provide a concentrated course series over the summer.

In 1977 it was argued that child care workers in central and eastern Oregon faced the problems of having no local training available and were located too faraway from Portland to participate in the regularly scheduled child care treatment and assessment course. Another special summer version was funded on this basis and its evaluation is the subject of this paper. It was delivered at The Dalles, Oregon over a four month period and employed the two-day workshop format. The training was made available to twenty five persons involved in various child care settings in central and eastern Oregon. 


\section{PROCEDURES}

The Child Care Treatment and assessment course is designed to provide training for child care practitioners in order to expand their knowledge and skill base, enhance their competence and job performance, encourage professional growth and upgrade the level of care provided to children from professional care givers. A variety of programs were represented by the participants. Individuals from five residential, two secure residential, three day treatment, five day care (one of these worked with adults as a trainer) and five pre-school settings were involved. Their tenure as child care practitioners ranged from one to twenty years with a mean of seven years.

The instructional philosophy adopted for delivery of the course are described by Knowles (1970) and Jenkins (1951) They parallel the contentions made in the child care literature concerning the need to provide child care personnel with uniquely developed training. They assert that adults differ significantly over how children learn and must, consequently, be educated differently. In order to successfully educate adults they must be respected as co-learners with the instructors and their independence, maturity, background of knowledge and experience, motivation for participating in the learning experience and resistance to change must also be respected. 
The instructional method also placed a great deal of emphasis on modeling and role play techniques. Studies (Goldstein, 1973) have demonstrated the usefulness of modeling procedures to facilitate attraction to therapists and promote vacarious learning. Role play enhancers augment the amount of attitude change determined by the role playes. The importance of attitude was demonstrated by Drew (1973). While training low income mothers as child care aids he discovered that attitude change was the most significant aspect in improving the quality of care the mothers were able to give. The course instructors have incorporated these role play techniques by using themselves and the participants as behavioral models.

\section{Evaluation Procedures}

Three evaluation instruments were used to measure the impact of the course. The first instrument sought to reflect the participant centered orientation of the training method along with demographic information. The participants were asked to establish their own level of expected achievement as a result of taking the course. They were asked to identify their achievement expectations on a four point scale ranging from the worst to the best possible outcome. They were also asked to identify their expectations of instructor performance, also on a four point scale ranging from the worst to the best possible outcome. 
This questionnaire was administered to the participants during the first half of the first class. The questionnaire was re-distributed during the last half of the last class along with the second instrument. They were asked to identify which of the four levels of self achievement expectations and which of the four levels of trainer expectations they considered as having been met. They were also asked to explain why they had arrived at their conclusions. The third evaluation instrument was also administered at this time.

The third instrument sought to measure various criteria identified as valued training ingredients in the child care literature and was based on participants' self report. It contained one (number one) question about personal growth, two questions (number two and three) dealt with competency, two questions (number four and six) with information, one question (number five) with attitude and one question (number seven) with professionalism. There was also one question (number eight) which asked for participant satisfaction of the course. All questions were rated on a forced choice five point scale and each point on each scale was specifically defined. Participants were also provided with the opportunity to comment further on each question. Copies of the questionnaires can be found in the appendix.

The evaluation was conducted by this researcher 
under the auspices of the Regional Research Institute for Human Services at Portland State University and edited by one of its staff. 
CHAPTER IV

FINDINGS

General Reactions

Twenty of the twenty-one participants responded to an open-ended question which asked them to list comments, or suggestions, about the course. Five persons mentioned feeling rushed or overloaded by all of the material presented. This was the major negative criticism. All of the participants who responded stated some variation of feeling satisfied with the outcome and having benefited both professionally and personally by the experience. The following statements are quoted from participants questionnaires :

Everything served a purpose - even the least useful created growth.

...I found the material presented valuable and informative, new, refreshing and well thought out and delivered. I wish I could have spent more time on it. gram.

...could (idealistically) expand to a degree pro-

I appreciated the informal structure with room for flexibility.

I feel this course is one that all child care workers should experience.

I would lengthen it. I've gotten a fortune, I want all the wealth.

\section{SELF ACHIEVEMENT AND TEACHER EXPECTATIONS}

The participants were asked to identify four levels of outcomes (from worst to best) by which they might rate 
the achievement of their goals during the course and at the end of the course they were asked to decide whether they had "underachieved", a "better than reasonable achievement", or "extraordinary achievement." One participant stated he had "underachieved", five stated they had "reasonably achieved", twelve stated they had "better than reasonably achieved", and three stated they had "extraordinarily achieved" in relation to their goals.

The participant who felt he had "underachieved" explained that this was "due to events in my life" and was willing to make time after the course to meet the notebook requirement" . . according to my satisfaction." of the participants who felt they had "reasonably achieved", one felt he still has to sort some information out and one felt encumbered because he had heard some of the material elsewhere. The fifteen remaining participants felt that their achievement goals had been exceeded.

The most consistent component of this evaluation was in the area of teacher performance for which a similar scaling procedure was used. The participants unanimously agreed that the instructors' performance had been either "better than reasonable" or "extraordinary" and had in some way exceeded their best expectations. One participant, who's comment was highly representative, stated:

I can't believe they covered as much as they did, worked as hard as they did and still maintained a positive feeling toward the class and just being there. 
COURSE IMPACT

The participants were asked to answer eight questions related to how the course impacted on them personally, on their job performance and on their professional outlook. All course impact questions were self ratings made on a five point scale with space for an explanatory comment. In general the responses clustered around scale point 4 (five was highest) in the following order:

\section{Question}

1. Personal growth

2. Work functions

3. Job performance

4. Concepts

5. Orientation

6. Skills

7. Career

8. Satisfaction
Average Rating

4.33

3.75

4.24

4.33

3.57

4.12

4.00

3.66

The following is a detailed analysis of each course impact question:

Personal Growth

One of the central themes presented to the participants was the notion of the child care worker's role as a change agent in the lives of the children under their care. This idea was perpetuated in the methods used to teach the participants the particular assessment and treatment technology. 
Each participant was asked to first learn the assessment techniques in the classroom lectures, demonstrations and role plays, then the participants were asked to use the assessment techniques on themselves: they were asked to assess their own behavior and target a particular piece of it to change. This was followed by a classroom series on treatment planning and implementation and the participants were again asked to practice the technology on themselves: to develop, implement and evaluate a treatment plan on their targeted behavior.

The internal consequences of this teaching technique is twofold. First the participant, in a very short period of time, internalizes and becomes proficient in using the material. The second internal consequence is that the participant experiences the same dynamic (and often stressful) change and growth experienced by the children in his. care. Thus the participant, by using himself as a laboratory, masters the technology and passes through a period of dynamic growth and change in his life experience, thereby enhancing his competence as a change agent for the children in his care.

In an effort to measure this dynamic of course, participants were asked to rate the amount of personal growth they experienced as a result of taking the course. Three participants rated the question "2 - Some aspects enhanced and other aspects eroded my personal growth." Five partici- 
pants rated the question "4 - Mostly growth enhancing" and thirteen participants rated the question "5 - Extremely growth producing."

of the three low rating participants one said he felt he "grew with the people and material presented" and felt a "lack of indepth cognitive growth . . ." This person, while generally expressing high satisfaction with the material and instruction, also expressed desire for more classroom time, indicating that although the question was rated low, the aspect of the course the question had been designed to measure was in fact fulfilled. The second low rating participant stated that the eroding aspect to his personal growth was that it required great amounts of energy that he would normally expend elsewhere. The third low rating participant stated that this aspect of the course "brought on many stressful situations" and that he had a "long way to go in learning how to deal with stress."

of the eighteen high rating participants, most made statements about the degree of freedom, safety and encouragement they felt in making personal changes. Many felt they would continue to grow and change after the class and most made statements about ways their personal growth had positively affected their growth as professional child care workers. A statement from one participant reads:

Areas of growth positively affected - intimacy, assertiveness, health problems, staff relationships, professional confidence, personal confidence, social 
interactions, leadership capabilities, bringing myself together from several different places.

Work Functions and Job Performance

A requirement for membership in the course is that participants also be child care practitioners consequently it is also expected (and at times required) that the functional parts of the materials presented be immediately applied in the participants' work setting. A change in the participants' job characteristics may be a natural by-product. As the child care practitioner gains greater competence as a caregiver in the classroom and translates that competence to his work setting, the impact is likely to be an alteration, informally at first, of his on-theline functions. It also follows that his performance on the job will be positively impacted.

The participants were asked two questions designed to measure this aspect of the course. The first question asked them to rate the amount their work functions had changed and the second question asked them to rate the amount their job performance had changed.

Five participants rated the work function question as "3 - had no impact on what is expected of me as a child care worker" and one rated the question "2 - in some ways I am being called upon to perform more complex child care tasks and in some ways I am being looked upon as a staff person with strange ideas." Ten participants rated the 
question "4 - I am being looked upon as a staff person capable of performing more complex child care and treatment tasks." Three participants rated the question "5 I am being given new job functions and/or a new position of greater responsibility as a child care worker and/or therapist." One participant did not respond.

The low rating participant went on to explain that his job did not include child care and treatment activities and that he had ". . . decided that I want to expand to child care treatment and assessment." of the five participants who gave the question a neutral (3) rating, one stated that he held "a position where a lot was expected." Two stated that their own expectations had changed but their job situation had not. One stated that the changes had not yet occurred and he was hopeful. it would and one declined to comment. The participant who did not respond stated he had taken the summer off and was unable to respond. of the fourteen high scoring participants, one had gained greater job status prior to leaving the group home. Two were in school settings and, consequently, not working during the summer, but felt the course impact would be highly positive when they returned. They generally stated they perceived themselves as having greater respect from their peers and superiors, and either had or expected to have greater job responsibilities or felt they had a good grasp of what they needed to change in their work functions. 
On the job performance question, one participant rated the question " 1 - I have become less effective in my work." Four rated the question "2 - Some aspects of my performance have improved and others have deteriorated." Ten participants rated the question "4 - My job performance has mostly improved in effectiveness." And six participants rated the question "5 - The course has been extremely enhancing to my job performance."

The single lowest rating participant stated that "the negative impact had to do with "personal crisis" and not with the course. Of the other three low rating participants, one stated his abilities had become sharper but " . . burnout has increased." Another attributed performance deterioration to time away from work while taking the course.

of the sixteen high rating participants, four expected greater job performance when they resume their jobs in September, one stated the material was easy to share with peers and two mentioned gaining more techniques to draw from. Generally, the high scoring participants felt more competent to perform on the job. One comment, that is similar to that made by many participants, reads: "I have learned how to help the children I love."

Concepts, Orientation and Skill

The course materials were presented to the partici- 
pants on three different levels simultaneously. On one level, the theoretical material was presented in the traditional classroom lecture style common to most educational settings. On another level efforts were made to provide the participants with as much exposure to the child care philosophy being presented as possible and on another level, efforts were made to bring the participants to higher skill levels while validating their present knowledge base.

Participants were prepared to receive new conceptual material by attempts at creating a relaxed and comfortable environment prior by the instructor delivering the lecture material. In many cases the instructor would take the participants through a relaxation or gestalt exercise, thereby simultaneously teaching a technique while preparing the participants to receive the lecture. Similarly, they were asked to participate in an experiential exercise after each lecture designed to help them practice and internalize the material they had just encountered. This method of instruction was intended to aid the participants in absorbing vast amounts of conceptual material while increasing their skill levels immediately.

In order to measure these aspects of the course the participants were asked to state the amount their concepts about child care, orientation to child care and skill levels had changed.

Two of the participants rated the amount to which 
their concepts about child care had changed as "3 - . . mainly a refresher of what I knew; learned a few new concepts." Ten rated the question " 4 - I learned a number of new concepts." And nine rated the question "5 - . . . opened a whole new world of concepts." of the two neutral respondents one stated that although his child care concepts had not appreciably changed, they had become clearer and had enabled him to clarify them for himself and his co-workers. The other neutral scoring participant stated that the course had made the concepts he had more useful and pragmatic.

The nineteen participants who felt their concepts about child care had changed a great deal centered their comments around the material being workable and useful to them in their work with children. Most stated that the course had helped them accept a variety of child care techniques, find new perspectives, validated what they knew and/or helped them perceive their children differently. One participant seemed to capture the feeling of many with his comment, "brilliant material."

The question which asked the amount to which the participants orientation had changed drew three "2 - no change ..." responses and six "3 - I tend to view child care in a somewhat different way" responses. Seven participants rated the question " 4 - The way I view child care has changed in some significant ways. My style was significantly affected" and four scored the question "5 - A whole new way of viewing 
child care has opened up for me. I have learned to be comfortable with a whole new style."

Comments on this question ranged from the participants' feeling validated and enhanced: "My views have changed in not how I look at child care but in the different angles from which I look." to a seemingly complete metamorphosis: "I am considering a whole new approach to working with preschool age children."

Lastly participants were asked to rate the amount their skills had changed. Five responded with "3 - pretty much a validation of what $I$ have been doing, learned a few new skills", nine responded "4 - learned a number of new useful skills and feel good about using them,"and seven said "5 - I am constantly using the new skills I learned and feel more competent about child caring."

Gave me a freedom to use all my skills with a tools for expressing the "whys" of their use.

Learned some good new skills and theories and personal skills developed from information gathered.

\section{Career}

Because child care workers have a relatively high attrition rate, the course is designed to focus on the credibility and professionalization of the child care worker by helping the participants perceive their role with children in a context broader than what is often identifiable while he is working on the line. It is hoped that he will, at some time during the course, review his career 
choice in the light of the new information and technology he is being exposed to.

To assess this outcome the participants were asked to measure the amount of impact the course had had on their careers as child care workers. Two participants responded that "2 - I am still uncertain about my career goals as far as child care is concerned," three said "3 - Pretty much a validation that I have chosen the right career and job", nine rated the questions as "4 - I have become significantly encouraged to continue to grow as a child care worker in my job" and seven rated the question as "5 - My commitment to child care has become solid and a way of life above and beyond my job."

Most of the comments to this question indicated that the course had validated their career decision and/or caused them to become more committed to it. A representative statement came from one of the participants in a school setting who stated: "I want to take what I've learned and use it at the grade school level and special Ed. department."

Satisfaction

The course is traditionally given throughout the academic year to students paying regular Division of Continuing Education tuition, and it is assumed that their satisfaction with the instruction and materials is what motivates them to continue to buy the service throughout 
the year. The instructors and this evaluator were interested in determining the satisfaction with the course when the participants had no financial investment in it. In order to address this issue the participants were asked to rate the amount of satisfaction they had felt in terms of their willingness to pay the standard tuition fee.

One participant reported that "2 - If I had to pay tuition I would not have attended", nine responded with "3 - . . . I would still consider taking it", eight said "4 - I would definitely have taken the course, even having to pay the present tuition rate $(\$ 300-\$ 500) "$ and three responded with "5 - I would have taken this course at twice the tuition rate." The responses, both written and verbal indicated that the participants were generally willing to pay for the experience but realistically were not in a financial position that enabled them to do so. The following representative comments speak for themselves:

At 非, I would be without food for two months.

Knowing what I know, this course was almost invaluable to me. Two thousand dollars would have been a bargain.

I'm glad I didn't have to pay for the course - I appreciate all good education.

I would have taken 12 units of class through P.S.U. over a 2 year period because I cannot afford $\$ 300-\$ 500$ in one lump. 


\section{SUMMARY AND CONCLUSIONS}

Child care workers are in a vital position in the life of their charges. By using their position and role effectively, they may have profound therapeutic impact. This fact, however, has been traditionally negated because child care workers have been perceived as custodial persons: glorified baby sitters, fortunately, however, this situation is changing. Child care workers are advocating for and being recognized as professional treatment people.

As child care personnel become more and more recognized as professionals, the need for them to become better trained increases. Similarly, the need to develop training programs to deal with their uniqueness becomes critical. While training courses are available (Vanderven 1976), they are still being developed. The Child Care Treatment and Assessment course, in Oregon, is one of these and the summer 1977 course is the subject of this evaluation.

The evaluation demonstrated that the course participants consistently stated they were highly satisfied with the course and the instruction. They generally felt that the course had had a positive impact on them both personally and professionally. Most felt that the experience had enhanced their ability to deliver service to the children in their care. 
Negative responses were minimal and participants were often careful to explain that low ratings were in some way due to circumstances outside of the course itself. The evaluator, while administering the questionnaires observed several class hours and spoke to several participants. These observations and informal interviews confirmed the reports of the high degree of satisfaction.

It is clear that the child care treatment and assessment course is a viable contribution to child care training in Oregon as well as the child care field. It is also, however, limited in scope. Certainly a single training resource to Child Care workers in the entire state of Oregon is insufficient. Moreover, once practitioners have taken the course there is nothing more of its kind available. It seems reasonable that this course could evolve into an Associate level, Bachelors level and perhaps Masters level training in the near future. Training models are already available, such as the Child Mental Health Specialist in California, and Ray and Lin Peterson and Michael Ebner have laid the groundwork for similar training in Oregon. This evaluator recommends they expand the Child Care Treatment and Assessment course into a degree program. 
Alder, J. 1973 "The Child Care Counselor as Target of Transfered Behavior" Child Care Quarterly 2 (2), 98-106.

Barnes, $\mathrm{H}$ and Kelman, M. 1974 "From Slogans to Concepts: A Basis for Change in Child Care Work" Child Care Quarterly 3(1), 7-23.

Bayduss, G. Vital, J., Chorost, S., and Leibowitz, G. 1972 "A Diagnostic Reception Unit in a Residential Center: A new role for professional child care and a mandate for a plan of service" Child Care Quarterly (4), 235-251.

Beker, J. 1973 "The Annual Meeting of the American Orthopsychiatric Association" Child Care Quarterly 2 (3), 229-231.

Beker, J., 1973a "Editorial: Toward a Unified Conception of the Child Care Profession" Child Care Quarterly 2 (4), 237-239.

Beker, J. 1973b "Needs of Child Care Training Programs Report of a Mini-Survey Child Care Quarterly 2(4), 285-286.

Beker, J. 1975 "The Child Care Professional: An Agenda for professional role identity for employment and motility in today's service structure" Child Welfare 54,241-431.

Bettelheim, B. 1966 "Training the Child Care Worker in a Residential Center" American Journal of Orthopsychiatry $36,694-705$.

Birnbach, D. 1973 "Some Observations on the Dilemas and Pressures of the Child Care Job" Child Care Quarterly $2(2), 87-97$.

Daniels, M., Finck, L. and Woodruff, N. 1976 "A team Approach to Teaching a Developmental Point of View" Child Care Quarterly 5(3), 181-191.

Cordori, C. and Cowles, T. 1971 "The Problems of Selecting Adults for Child Care Training Programs: a Descriptive and Methodological Study" Child Care Quarterly 1 (1), 47-55.

Cunningham, G. 1975 "Proceedings of the 1974 Conference: Child Care Training for a Changing World" Child Care Quarterly 4 (1), 241-268. 
Cunningham, G. 1975 "Language and the Child Care Professional" Child Care Quarterly 4(1), 27-34.

Dinwiddie, F. 1974 "The Perilous Journey: A Training Monograph" Adolescence 9(35), 339-350.

Drew, J. 1973 "Training Child Care Aids" Children Today $2(5), 15-18$.

English, T. 1977 "The Child Care Worker: An Emerging Professional"unpublished monograph Lane County Youth Care Centers, Inc.

Foster, G. 1972 "A Federal Program to Establish a New Professional - The Child Development Associate" Child Care Quarterly 1(4), 301-302.

Foster, G. 1973 "Standards for CCW's: Report of the Standards Committee of the Washington Conference of Child Caring Institutions" Child Care Quarterly $2(1), 38-55$.

Foster, G. 1973a "The Development of Standards for Child Care Workers in Child Caring Institutions in New York: A proposal by the Association of Child Care Workers Child Care Quarterly 2(3), 216-218.

Gold, S and Mihic, V. 1971 "Changing Models in Therapy and Child Care" Child Care Quarterly 1(1), 13-20.

Goldsmith, J.M. 1976 "Residential Treatment: the paradox of new promises" American Journal of Orthopsychiatry $46(3), 425-33$.

Goldstein, A.P. Structured Learning Therapy Academic Press: N.Y. 1973.

Goocher, B. 1971 "The Child Care Worker as a Agent of Change" Child Care Quarterly 1(1), 7-12.

Gordetsky, S. 1974 "Observing and Recording as a Child Care Worker: Daily Recording". Child Care Quarterly 3(4), 237-245.

Hughes, T. 1973 "Comment: On the Career Ladder in Child Care" Child Care Quarterly 2(3), 219-220.

Jenkins, D. 1951 "On Educating Adults" The University of Michigan School of Education Bulletin 22(7). 
Katz, L. 1970 "Teaching in Preschools: Roles and Goals" Children 17,42-48.

Katz, D. 1975 "Feasibility of University Training for Child Development Professionals" Child Care Quarterly 4(1), 18-26.

Klein, W. 1975 "Evaluation and Child Care Training Programs" Child Care Quarterly 4(4), 258-261.

Klein, J. and Weathersby, R. 1973 "The Child Development Associates: New Professionals, New Training Strategies" Children Today 2(5), 2-6.

Knowles, M.J. The Modern Practice of Adult Education. New York: Association Press, 1970.

Kuntz, D. 1976 "A Systematic Supervisory Procedure for Child Care Training" Child Care Quarterly 5(1), 9-18.

Larsen, L. 1973 "Some Administrative Contributions to Enhancing the Child Care Role in a Team Approach" Child Care Quarterly 2(4), 240-244.

Maier, H. 1963 Training Child Care Staff, N.Y.: Child Welfare League of America, 62-81.

Nicholson, M.L. 1975 "Child Care Practice and the Passions of Today: Some Propositions." Child Care Quarterly $4(1), 35-44$.

Peters, D.L., Cohen, A.S. and McNicho1, M. 1974 "The Training and Certification of Early Childhood Personnel" Child Care Quarterly 3(1), 39-53.

Portnoy, S.W., Billier, H.B. and Davids, A. 1972 "The Influence of the Child Care Worker in Residential Treatment" American Journal of Orthopsychiatry $42(4), 717-22$.

Rieger, N.I. 1972 "Changing Concepts in Treating Children in a State Mental Hospital" International Journal of Child Psychotherapy 1(4), 89-113.

Rieger, N.I. 1972 "From State Hospital to Satellite Home" Exchange, October, State of California, Health and Welfare Agency, Department of Health 34-46. 
Rieger, N.I. 1973 "The Birth of a New Professional- The Child Care Specialist" Exchange, November/December, State of California, Health and Welfare Agency, Department of Health 13-19

Rieger, N.I. "Why The Need for a New Professional in the Child Mental Health Field" paper presented at the American, Orthopsychiatric Association 51st Annual Conference - at a joint meeting with the American Association of Workers for Children, Inc. San Francisco, California, April 10, 1974.

Rieger, N.I. and Devries, A.G. 1974 "The Need and Some Specific Suggestions For a Standardized Training Program For a New Professional: The Child Mental Health Specialist" Child Care Quarterly 3(3), 177-187.

Rieger, N.I. and Devries, A.G. 1974a The Child Mental Health Specialist: A New Professional" American Journal of Orthopsychiatry $44(1), 150-158$.

Rieger, N.I. and Devries, A.G. 1977 "A Model Training Program for Child Mental Health Specialists" Hospital and Community Psychiatry 28(9), 690-693.

Rozentals, V., Piper, A.C. and Whipple, H. 1974 "Professionalizing the Child Care Worker" Child Welfare 53(9), 563-69.

Seifert, K. 1975. "The Best Man for the Job" Child Care Quarterly 4(3), 188-193.

Toigo, R. 1975 "Child Care Manpower Development: A Literature Review" Child Care Quarterly 4(1), 6-17

VanderVen, K. (ed) 1975 "Proceedings of the 1974 Conference: Child Care Training for a Changing World" Child Care Quarterly 4(4), 241-268.

VanderVen, K. 1976 "A Compendium of Training Programs in the Child Care Profession in the U.S. and Canada" Child Care Quarterly 5(4), 319-29.

Vandivier, F. 1975 "Selecting and Educating Future Child Care Professionals" Child Care Quarterly 4(4) 254-56.

Weintrob; A. 1974 "Changing Population in Adolescent Residential Treatment: New. Problems for Program and Staff" American Journal of Orthopsychiatry 44(4) 604-10. 
Whittiker, J. 1973 "The Child Care Continuum: New Directions for Children's Residential Centers" Child Care Quarterly 2(2), 124-135.

Whittiker, J. 1974 "A Further Comment on Barns and Kelman" Child Care Quarterly 3(2), 130-132.

Zigler, E. 1972 "A New Child Care Profession: The Child Development Associate" Child Care Quarterly 1(3), 183-186. 
APPENDIX 
1) Age

2) Sex

3) Single_Married Other(specify)

4) Income per month\$ 5) O.A.C.C.W. yes no

6) My role in child-care (job/position)

7) How long in present job/position

8) How long employed in child-care

9) Sex of children I work with

10) Age range of children I work with

11) Type of facility (residential, day treatment, etc.)

12) How did you find out about this course

13) What factors made you decide to take this course

14) As a result of taking this course, what would you consider: A. an UNDER achievement for yourself

B. a REASONABLE achievement for yourself

C. a BETTER THAN REASONABLE achievement for yourself

D. an EXTRAORDINARY achievement for yourself

15) From the instructors of the course, what would you consider:

A. a POOR performance

B. a REASONABLE performance

C. a BETTER THAN REASONABLE performance

D. an EXTRAORDINARY performance 
During the first class you scaled your goels for the course in terms of achievément. Please indicate if you consider youreelf as having: (oircle one)

1
underachieved $\begin{gathered}2 \\ \begin{array}{c}\text { reasonably } \\ \text { achieved }\end{array}\end{gathered} \begin{gathered}3 \\ \begin{array}{c}\text { better than } \\ \text { reasonably } \\ \text { achieved }\end{array}\end{gathered} \begin{gathered}4 \\ \text { extraordinarily } \\ \text { achieved }\end{gathered}$

Please explain:

During the first class you scaled your expectations of the instructors of the course. Please indicate if you consider the instructors as having: (circle one)

$\begin{array}{cccc}1 & 2 & 3 & 4 \\ \text { performed } & \text { performed } & \text { performed } & \text { performed } \\ \text { poorly } & \text { beasonably } & \text { extra- } \\ \text { than } & \text { reasonably } & \text { ordinarily }\end{array}$

Please explain, 


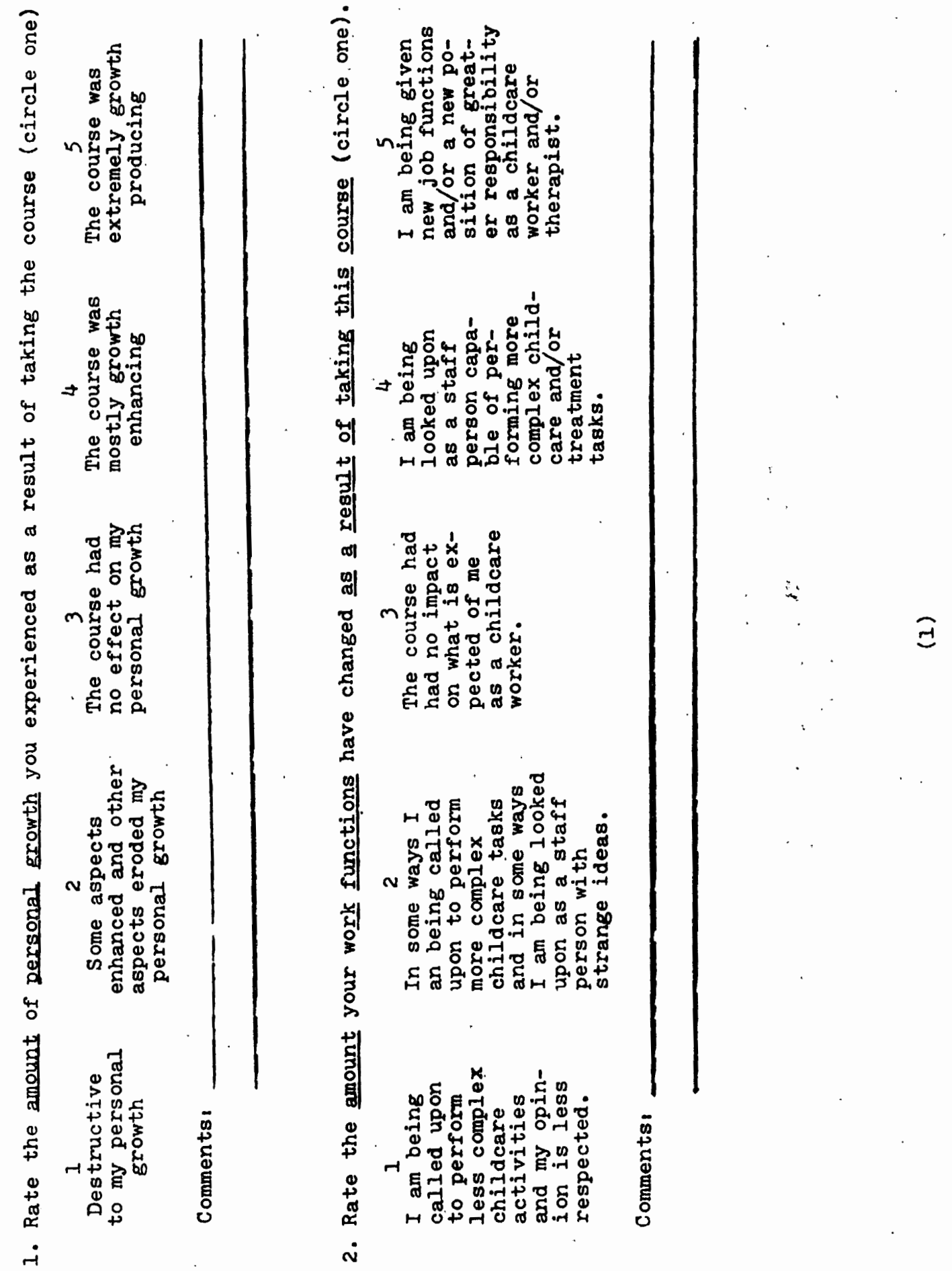




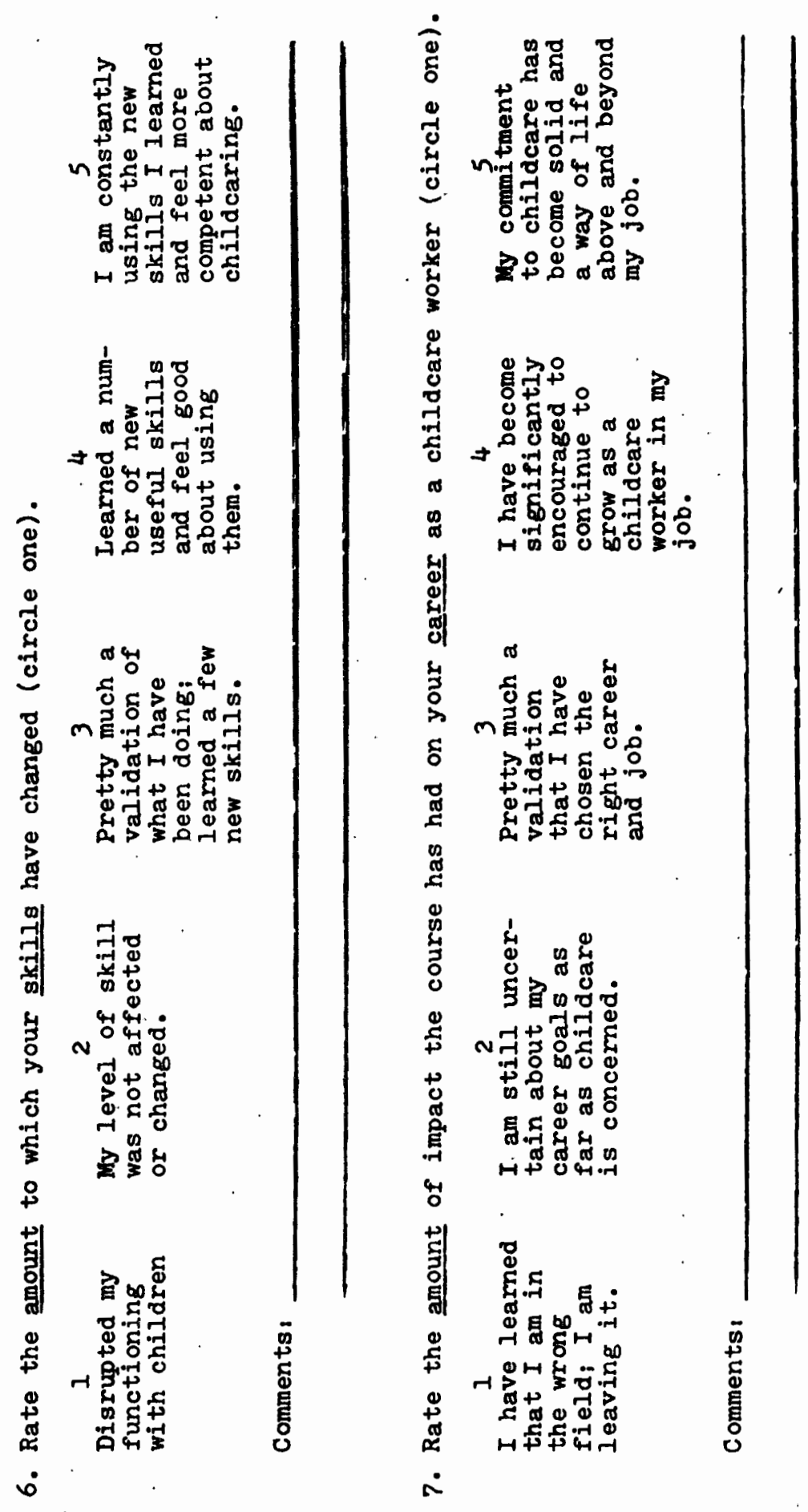

$\widehat{0}$ 


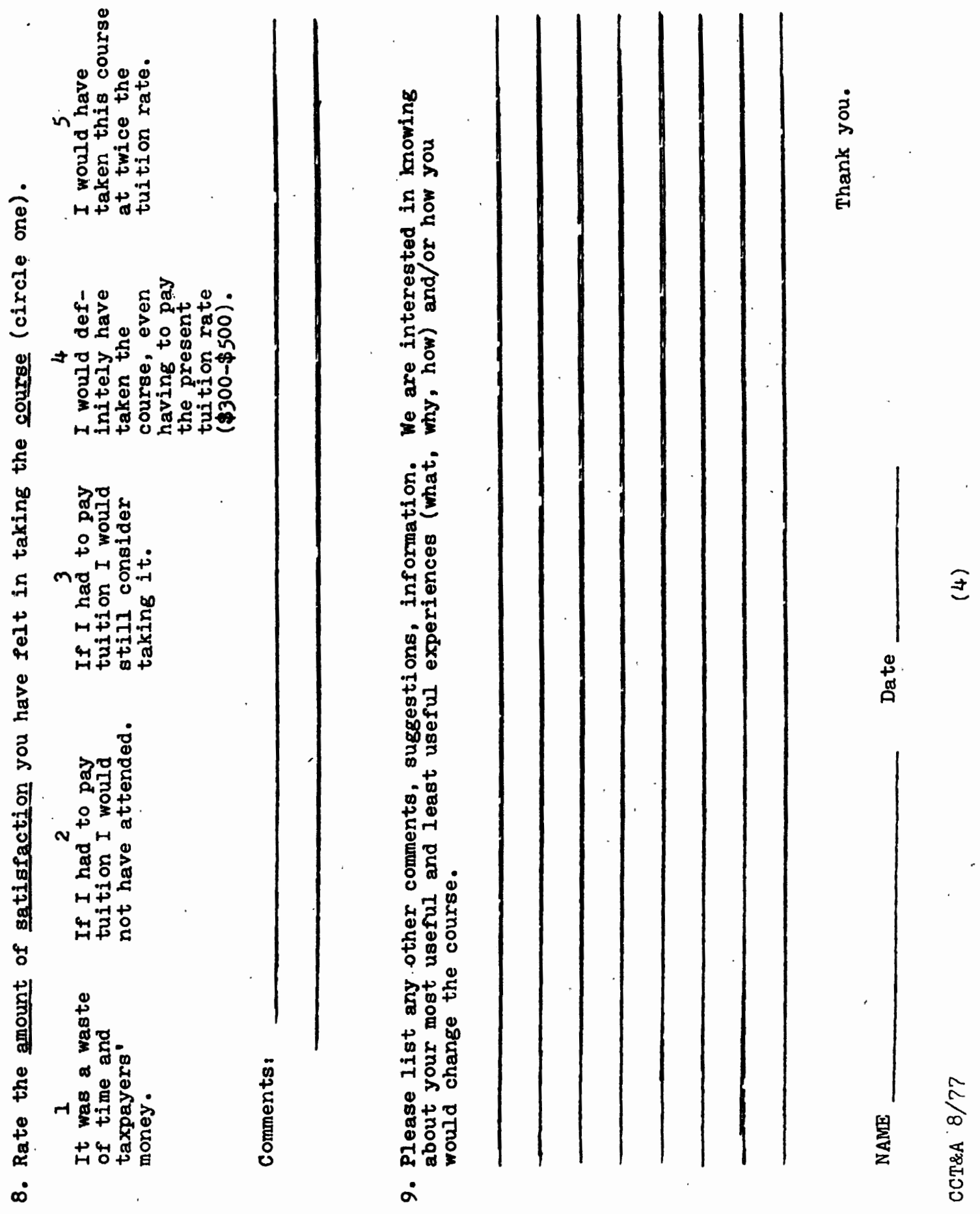

